\title{
Rejuvenation Heat Treatment of the Second-Generation Single-Crystal Superalloy DD6
}

\author{
Zhen-Xue Shi ${ }^{1} \cdot$ Shi-Zhong Liu ${ }^{1} \cdot$ Jia-Rong Li $^{1}$
}

Received: 14 June 2015/Revised: 30 August 2015/Published online: 12 October 2015

(C) The Chinese Society for Metals and Springer-Verlag Berlin Heidelberg 2015

\begin{abstract}
The second-generation single-crystal superalloy DD6 with [001] orientation was prepared by screw selecting method in the directionally solidified furnace. The long-term aging of the alloy after full heat treatment was performed at $1100{ }^{\circ} \mathrm{C}$ for $400 \mathrm{~h}$. Then the rejuvenation heat treatment $1300{ }^{\circ} \mathrm{C} / 4 \mathrm{~h} / \mathrm{AC}+1120{ }^{\circ} \mathrm{C} / 4 \mathrm{~h} / \mathrm{AC}+870{ }^{\circ} \mathrm{C} / 24 \mathrm{~h} / \mathrm{AC}$ was carried out. The stress rupture properties were investigated at $760{ }^{\circ} \mathrm{C} / 800 \mathrm{MPa}, 850{ }^{\circ} \mathrm{C} / 550 \mathrm{MPa}, 980{ }^{\circ} \mathrm{C} / 250 \mathrm{MPa}$ and $1100{ }^{\circ} \mathrm{C} / 140 \mathrm{MPa}$ after different heat treatments. The microstructures of the alloy at different conditions were studied by SEM. The results show that $\gamma^{\prime}$ phase of the alloy became very irregular and larger after long-term aging at $1100{ }^{\circ} \mathrm{C}$ for $400 \mathrm{~h}$. A very small amount of needle-shaped TCP phase precipitated in the dendrite core. The coarsened $\gamma^{\prime}$ phase and TCP phase dissolved entirely after rejuvenation heat treatment. The microstructure was restored and almost same with the original microstructure. The stress rupture life of the alloy decreased in different degrees at various test conditions after long-term aging. The stress rupture life of the alloy after rejuvenation heat treatment all restores to the original specimen more than $80 \%$ at different conditions. The microstructure degradation of the alloy during long-term aging includes coarsening of the $\gamma^{\prime}$ phase, P-type raft and precipitation of TCP phase, which results in the degeneration of stress rupture property. The rejuvenation heat treatment succeeds in restoring the original microstructure and stress rupture properties of the alloy.
\end{abstract}

KEY WORDS: Single-crystal superalloy; DD6; Rejuvenation heat treatment; Stress rupture properties

\section{Introduction}

Single-crystal superalloys have been widely used as major material for modern aeroengine turbine blades because of their superior mechanical properties at elevated temperature [1-3]. Turbine blades are one of the most important hot section components in gas turbine systems. They are subjected to complex combination of inhomogenous stresses and temperature distribution as well as high-

Available online at http://link.springer.com/journal/40195

Zhen-Xue Shi

shizhenxue@126.com

1 Science and Technology on Advanced High Temperature Structural Materials Laboratory, Beijing Institute of Aeronautical Materials, Beijing 100095, China temperature corrosion and oxidation environment [4]. The mechanical properties of these blades are largely affected by their microstructures. The degradation results mainly from $\gamma^{\prime}$ phases coarsening and the generation of TCP phases servicing at high temperature [5]. Material degradation necessitates the periodic replacement of hot section components and represents a very significant cost $[6,7]$. Most of the degradations are reversible, and many studies have displayed the probability of rejuvenation of the alloys after service [8]. It is suggested that the restoration of microstructure and properties of the alloys after service can depend on the proper rejuvenation heat treatment [9]. Many reports have been published on the rejuvenation of nickel base superalloys in the past few years, but there is only a small amount of investigation involved in single-crystal superalloys. The DD6 alloy developed by Beijing Institute of Aeronautical Materials has the properties of the alloy 
similar to those of other second-generation single-crystal superalloys, such as PWA1484, RenéN5 and CMSX-4 [10]. In recent years, many studies have been carried out to investigate the properties of DD6 alloy [11-13]. However, the investigation on rejuvenation of the alloy after service is still limited. For the sake of application and development of the single-crystal superalloy DD6, it is important to investigate the rejuvenation heat treatment of the alloy to extend the lifetime of turbine blades.

\section{Experimental}

The nominal chemical compositions of the DD6 alloy are listed in Table 1. The single-crystal superalloy samples with [001] orientation were cast by means of crystal selection method in the directionally solidified furnace with hightemperature gradient. The crystal orientations of the samples were analyzed by Laue X-ray back-reflection method, and the crystal orientation deviations of the samples were maintained within $10^{\circ}$ from the [001] orientation. The standard heat treatment of the samples was carried out in accordance with following heat treatment regime: $1290{ }^{\circ} \mathrm{C} /$ $1 \mathrm{~h}+1300{ }^{\circ} \mathrm{C} / 2 \mathrm{~h}+1315^{\circ} \mathrm{C} / 4 \mathrm{~h} / \mathrm{AC}+1120^{\circ} \mathrm{C} / 4 \mathrm{~h} / \mathrm{AC}+$ $870{ }^{\circ} \mathrm{C} / 32 \mathrm{~h} / \mathrm{AC}$, where $\mathrm{AC}$ means air cooling. Long-term aging was used to simulate the service conditions of the turbine blade. A part of specimens were long-term aged at $1100{ }^{\circ} \mathrm{C}$ for $400 \mathrm{~h}$. At last, the rejuvenation heat treatment $1300{ }^{\circ} \mathrm{C} / 4 \mathrm{~h} / \mathrm{AC}+1120{ }^{\circ} \mathrm{C} / 4 \mathrm{~h} / \mathrm{AC}+870{ }^{\circ} \mathrm{C} / 24 \mathrm{~h} / \mathrm{AC}$ was carried out. The standard cylindrical specimens for stress rupture properties tests were machined at different heat treatment conditions, and the stress rupture property tests were conducted at $760{ }^{\circ} \mathrm{C} / 800 \mathrm{MPa}, 850{ }^{\circ} \mathrm{C} / 550 \mathrm{MPa}, 980{ }^{\circ} \mathrm{C} /$ $250 \mathrm{MPa}$ and $1100{ }^{\circ} \mathrm{C} / 140 \mathrm{MPa}$ in air using a DST-5 testing machine with furnace attachment. The samples were etched with $5 \mathrm{~g} \mathrm{CuSO}_{4}+25 \mathrm{~mL} \mathrm{HCl}+20 \mathrm{~mL} \mathrm{H}_{2} \mathrm{O}+5 \mathrm{~mL}$ $\mathrm{H}_{2} \mathrm{SO}_{4}$ which dissolves the $\gamma^{\prime}$ phase. Microstructures of the alloy at different conditions were examined by using $\mathrm{S} 4800$ scanning electron microscope.

\section{Results and Analysis}

\subsection{Microstructures after Different Heat Treatment Conditions}

Figure 1 shows the microstructure of DD6 alloy after standard heat treatment. It can be seen that the primary $\gamma^{\prime}$

Table 1 Nominal chemical compositions of DD6 alloy (wt\%)

\begin{tabular}{lllllllllll}
\hline $\mathrm{Cr}$ & $\mathrm{Co}$ & $\mathrm{Mo}$ & $\mathrm{W}$ & $\mathrm{Ta}$ & $\mathrm{Re}$ & $\mathrm{Nb}$ & $\mathrm{Al}$ & $\mathrm{Hf}$ & $\mathrm{C}$ & $\mathrm{Ni}$ \\
\hline 4.3 & 9 & 2 & 8 & 7.5 & 2 & 0.5 & 5.6 & 0.1 & 0.006 & Bal. \\
\hline
\end{tabular}

and $\gamma / \gamma^{\prime}$ eutectic dissolved completely after the high-temperature solution treatment. The cubical $\gamma^{\prime}$ phase is regularly arranged along [100] direction. The average length of the $\gamma^{\prime}$ precipitates edge is about $0.45 \mu \mathrm{m}$, the width of the $\gamma$ matrix channel is about $0.05 \mu \mathrm{m}$, and the volume fraction of the $\gamma^{\prime}$ phase in the alloy is more than $60 \%$.

Figure 2 illustrates the microstructures of (001) plane of the alloy after long-term aging at $1100{ }^{\circ} \mathrm{C}$ for $400 \mathrm{~h}$. It is shown that the adjacent $\gamma^{\prime}$ particles met and fused together along the cubic direction. The $\gamma^{\prime}$ particles became very irregular and larger. Some of $\gamma$ phase matrix became no longer continuous. During long-term aging exposure, the $\gamma^{\prime}$ particles grew driven by the reduction in interface energy correlated with reduction in interface area [14]. A very small amount of needle-shaped TCP phases had already been observed in the dendrite core. The chemical composition of the TCP phase is shown in Table 2. It is displayed that $\mathrm{Re}$ and $\mathrm{W}$ are enriched in the TCP phase. The formation of the TCP phase in the Ni-based single-crystal superalloys has generally been attributed to the supersaturation of the refractory elements $(\mathrm{Re}, \mathrm{W})$ within the disordered $\gamma$ phase [15].

Figure 3 illustrates the microstructures of the alloy after rejuvenation heat treatment. It displays that the coarsened $\gamma^{\prime}$ phase and TCP phase dissolved entirely after heat treatment at high temperature. It comprises more than $60 \%$ $\gamma^{\prime}$ precipitates in cube form with $0.43 \mu \mathrm{m}$ and $\gamma$ phase channel which are almost same as the original microstructure. During rejuvenation, the role of heat treatment is to restore the microstructure to its original condition as much as possible [8]. The microstructure was restored by two stages. First, the alloy was heated to $1300{ }^{\circ} \mathrm{C}$ for $4 \mathrm{~h}$ to dissolve all the $\gamma^{\prime}$ phase and TCP phase in order to achieve a single-phase microstructure and was

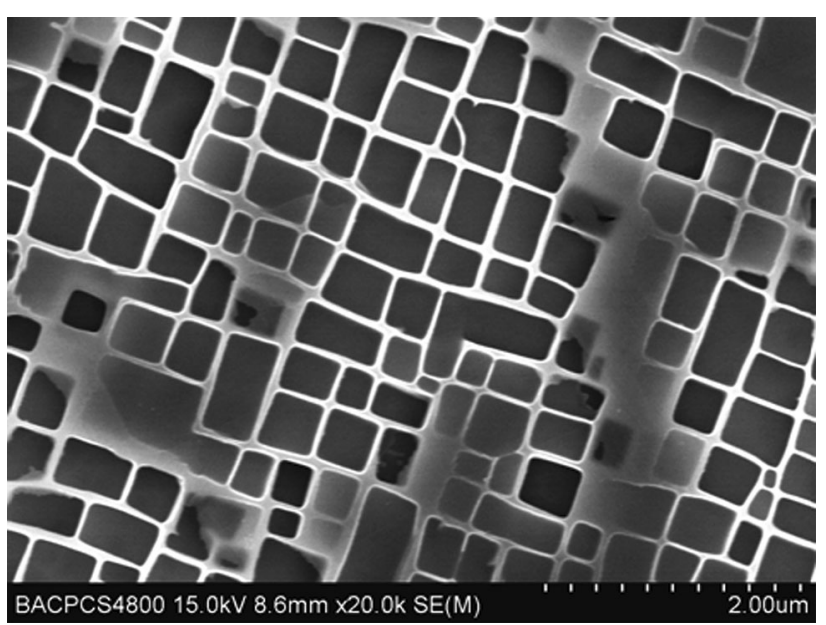

Fig. 1 Microstructure of DD6 single-crystal superalloy after standard heat treatment 

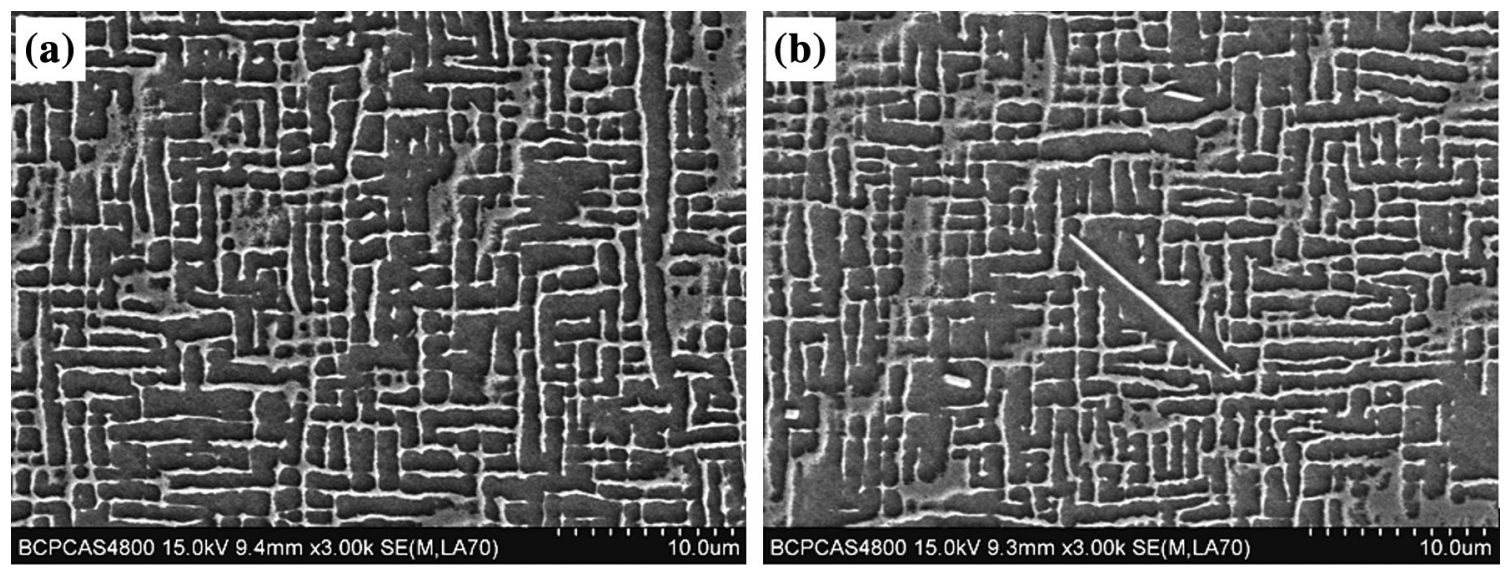

Fig. 2 Microstructures of the alloy after long-term aging at $1100{ }^{\circ} \mathrm{C}$ for $400 \mathrm{~h}$ : a $\gamma^{\prime}$ phase; b TCP phase

Table 2 Chemical composition of the TCP phase in the alloy after long-term aging at $1100{ }^{\circ} \mathrm{C}$ for $400 \mathrm{~h}(\mathrm{wt} \%)$

\begin{tabular}{cccccccc}
\hline $\mathrm{Al}$ & $\mathrm{Cr}$ & $\mathrm{Co}$ & $\mathrm{Mo}$ & $\mathrm{Re}$ & $\mathrm{Ta}$ & $\mathrm{W}$ & $\mathrm{Ni}$ \\
\hline 2.3 & 4.1 & 7.6 & 2.8 & 13.2 & 6.2 & 11.1 & Bal. \\
\hline
\end{tabular}

then cooled quickly to room temperature to form the fine $\gamma^{\prime}$ precipitates (Fig. 3a). Second, a two-step aging treatment $\left(1120^{\circ} \mathrm{C} / 4 \mathrm{~h} / \mathrm{AC}+870{ }^{\circ} \mathrm{C} / 24 \mathrm{~h} / \mathrm{AC}\right)$ was followed to obtain the desired uniform $\gamma / \gamma^{\prime}$ duplex microstructure (Fig. 3b). The rejuvenation treatment of the alloy is very similar as the standard heat treatment. However, there were some differences between them. The homogenization treatment $\left(1290{ }^{\circ} \mathrm{C} / 1 \mathrm{~h}+1300{ }^{\circ} \mathrm{C} / 2 \mathrm{~h}\right)$ before the solution treatment must be carried out to avoid incipient melting with a significant fraction of $\gamma-\gamma^{\prime}$ eutectic in the interdendritic region for the cast alloy in the standard heat treatment. Moreover, the rejuvenation must not have such a high solution treatment temperature to make the probability of recrystallization as little as possible because there is no $\gamma-\gamma^{\prime}$ eutectic in the alloy after standard heat treatment and long-term aging.

\subsection{Stress Rupture Properties}

The stress rupture properties of DD6 alloy after different heat treatments at various test conditions are shown in Table 3. Every datum is an average of three tests. It can be seen that the alloy has long stress rupture life at different test conditions, which indicates that the alloy has excellent stress rupture property [10].

The stress rupture lives of the alloy all decrease in different degrees at various test conditions after long-term aging. At $760{ }^{\circ} \mathrm{C} / 800 \mathrm{MPa}$ and $850{ }^{\circ} \mathrm{C} / 550 \mathrm{MPa}$, the stress rupture life is about 25 and $22 \%$ of original specimen, respectively. However, it is about 57 and $46 \%$ of original specimen at $980{ }^{\circ} \mathrm{C} / 250 \mathrm{MPa}$ and $1100{ }^{\circ} \mathrm{C} / 140 \mathrm{MPa}$, respectively. It indicates that long-term aging at high temperature has much effect on the stress rupture properties of the alloy at intermediate temperature and high stress.
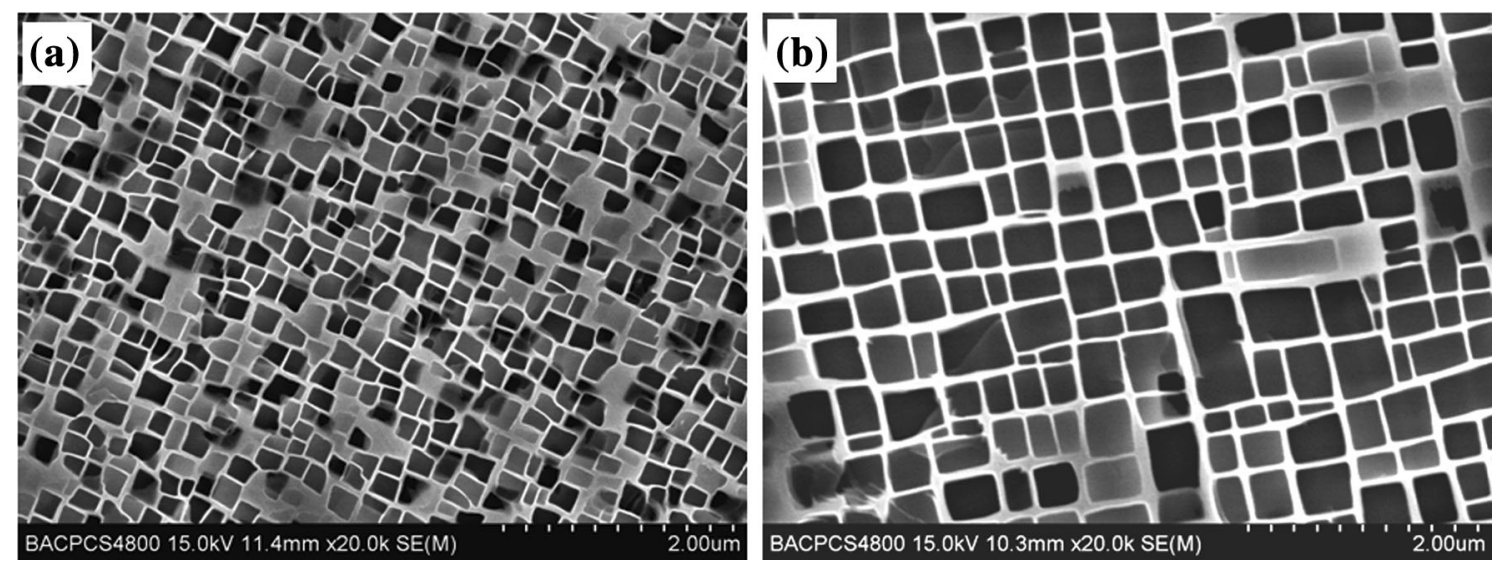

Fig. 3 Microstructures of the alloy after rejuvenation heat treatment: a solution heat treatment; $\mathbf{b}$ solution and aging heat treatment 
Table 3 Stress rupture properties of DD6 alloy after different heat treatments under different test conditions

\begin{tabular}{|c|c|c|c|c|c|c|}
\hline \multirow[t]{2}{*}{ Test condition } & \multicolumn{2}{|c|}{ Standard heat treatment } & \multicolumn{2}{|c|}{ Long-term aging } & \multicolumn{2}{|c|}{ Rejuvenation heat treatment } \\
\hline & $t(\mathrm{~h})$ & $\delta(\%)$ & $t(\mathrm{~h})$ & $\delta(\%)$ & $t(\mathrm{~h})$ & $\delta(\%)$ \\
\hline $760{ }^{\circ} \mathrm{C} / 800 \mathrm{MPa}$ & 208.4 & 28.3 & 52.5 & 36.6 & 174.5 & 32.1 \\
\hline $850^{\circ} \mathrm{C} / 550 \mathrm{MPa}$ & 603.5 & 26.7 & 133.5 & 22.5 & 662.8 & 26.9 \\
\hline $980{ }^{\circ} \mathrm{C} / 250 \mathrm{MPa}$ & 254.5 & 36.6 & 145.1 & 46.7 & 250.9 & 36.4 \\
\hline $1100^{\circ} \mathrm{C} / 140 \mathrm{MPa}$ & 155.2 & 8.1 & 70.9 & 42.6 & 124.3 & 21.2 \\
\hline
\end{tabular}

As mentioned above, the microstructure degradation of the alloy during long-term aging at $1100{ }^{\circ} \mathrm{C}$ includes coarsening of $\gamma^{\prime}$ precipitates and precipitation of TCP phase. Therefore, it can be deduced reasonably that the degeneration of stress rupture properties after long-term aging is dominated by these microstructure degradations. The stress rupture life of the alloy after rejuvenation heat treatment all restores to the original specimen more than $80 \%$ at different conditions.

\subsection{Microstructure of Ruptured Specimens}

The microstructure on the longitudinal section in the ruptured specimens of the alloy at different conditions was observed by SEM. Figure 4 illustrates the microstructure apart from fracture surface $1 \mathrm{~cm}$ of the ruptured specimens after standard heat treatment. It can be seen from the observation that a little change in $\gamma^{\prime}$ precipitate morphology occurs at the condition of $760{ }^{\circ} \mathrm{C} / 800 \mathrm{MPa}$ (Fig. 4a). The vertical $\gamma$ matrix becomes thinner, and horizontal $\gamma$ matrix becomes thicker slightly. No appreciable thickening of the $\gamma^{\prime}$ precipitates seems to take place. The lateral merging of the $\gamma^{\prime}$ precipitates has already begun along the direction of the applied stress at the condition of $850{ }^{\circ} \mathrm{C} / 550 \mathrm{MPa}$ (Fig. 4b). The lateral extension of the $\gamma^{\prime}$ precipitates is well under way. Its thickness along the direction of the applied stress has increased slightly, but the striking point is the drastic thickening of the $\gamma$ phase. The $\gamma$ phase is surrounded by the $\gamma^{\prime}$ phase forming wavy and branching platelets at condition of $980{ }^{\circ} \mathrm{C} / 250 \mathrm{MPa}$ (Fig. 4c). The feature is that the $\gamma$ phase is no longer continuous. They are islands and thus entirely surrounded by the $\gamma^{\prime}$ phase. At condition of $1100{ }^{\circ} \mathrm{C} / 140 \mathrm{MPa}$, the thickness of the $\gamma$ phase continues to increase and is generally thicker than a micron (Fig. 4d). No TCP phase can be seen at four experimental conditions.

The cubic $\gamma^{\prime}$ phase gradually changed into a raft structure because of the directional diffusion of the elements. In the process, the diffusion and redistribution of the alloying elements in the $\gamma^{\prime}$ and $\gamma$ phases have occurred [16]. With the action of the applied stress and the misfit stress at high temperature, in the $\gamma^{\prime}$ phase, the forming elements $\mathrm{Al}, \mathrm{Ta}$, $\mathrm{Nb}$, Hf diffuse to the vertical channels, promoting the $\gamma^{\prime}$ phase growth perpendicular to [001] direction. At the same time, the $\gamma$ phase-forming elements $\mathrm{Cr}, \mathrm{Co}, \mathrm{W}, \mathrm{Mo}$, Re diffuse to the horizontal channels in the reverse orientation to increase the width of the $\gamma$ matrix. Under the condition of temperature and stress, the $\gamma^{\prime}$ rafted structure is gradually formed. The higher the temperature is and the faster atoms diffuse, the faster $\gamma^{\prime}$ phase grows and rafts. So with the rise of the temperature, the thickness of $\gamma^{\prime}$ rafts turns bigger.

The microstructures apart from fracture surface $1 \mathrm{~cm}$ of the ruptured specimens after long-term aging are shown in Fig. 5. The $\gamma^{\prime}$ precipitate had rafted at four experimental conditions. The $\gamma^{\prime}$ rafts have a tendency to thicken with the increase in the temperature, and their morphologies are obviously different from those after standard heat treatment. It can be seen that most of rafts in the microstructure are N-type, which means the rafts are normal to the stress axis. A small part of the rafts are P-type, which means the rafts are parallel to the stress axis, as shown in Fig. 5b, e, h and $\mathrm{k}$. The rafts after long-term aging can be normal to anyone at three directions [001], [100] and [010], as shown in Fig. 2a. Under the applied tensile stress, on the one hand, the N-type rafts which were normal to the stress axis continually thickened, and on the other hand, the P-type rafts which were parallel to the stress axis transformed gradually into the N-type structure. TCP phases formed in the long-term aging process can be seen at four experimental conditions. Moreover, it is brittle and became the sites of the crack initiation and easy ways for the crack propagation during stress rupture test [17], as shown in Fig. $5 \mathrm{c}, \mathrm{f}, \mathrm{i}$ and $\mathrm{l}$. It is one of the reasons for the decrease in stress rupture life of specimens after long-term aging.

The microstructures apart from fracture surface $1 \mathrm{~cm}$ of the ruptured specimens after rejuvenation heat treatment are shown in Fig. 6. The morphology of the $\gamma^{\prime}$ phase at four experimental conditions is almost same with the specimens after standard heat treatment. This is mainly due to the effect of rejuvenation heat treatment.

\section{Discussion}

The nickel-based single-crystal superalloys are mainly strengthened by a high volume fraction of the $\gamma^{\prime}$ phases embedded coherently in the $\gamma$ matrix. The stress rupture 

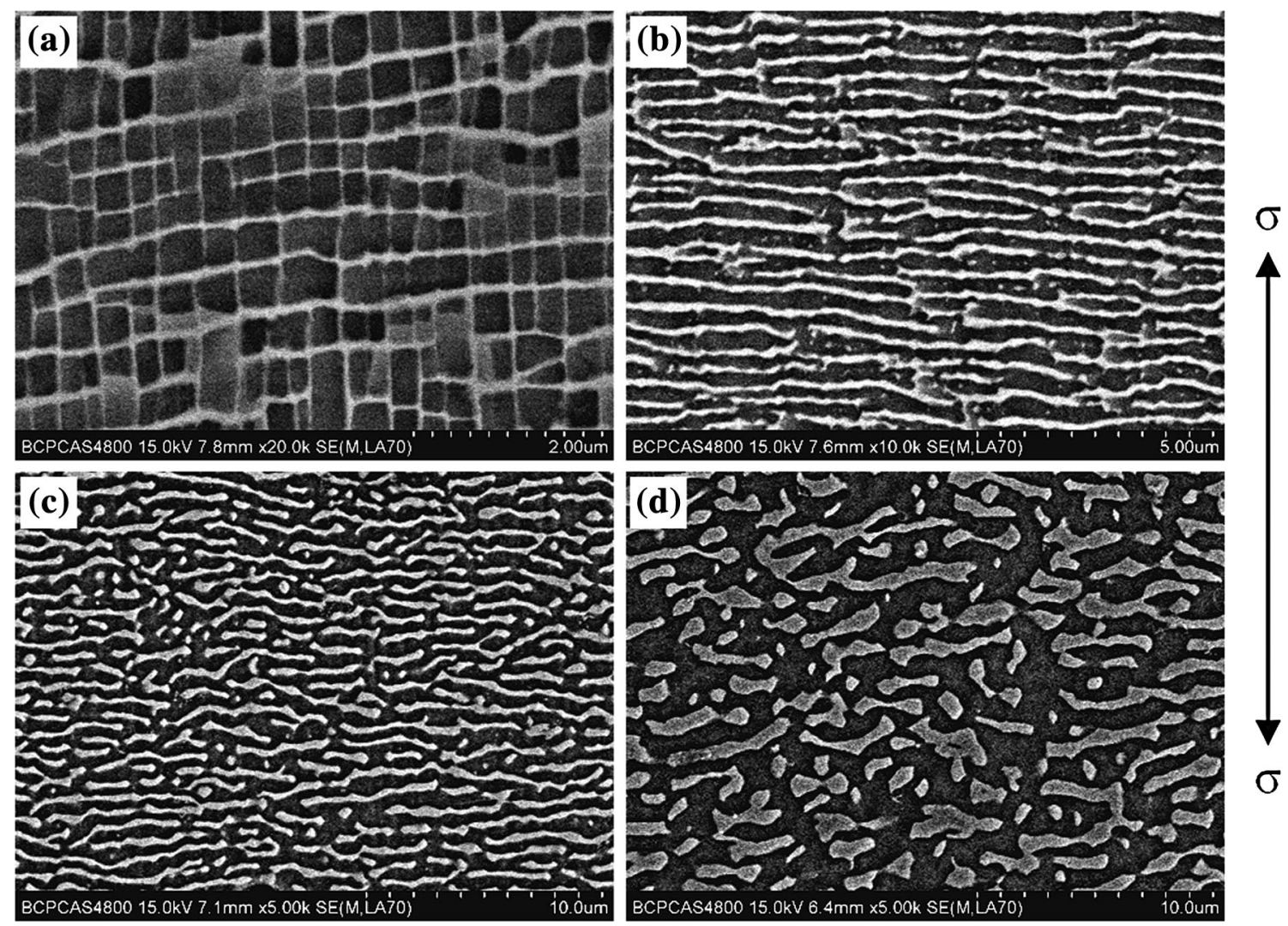

Fig. 4 Microstructures of the stress-ruptured specimens after standard heat treatment: a $760{ }^{\circ} \mathrm{C} / 800 \mathrm{MPa} ; \mathbf{b} 850{ }^{\circ} \mathrm{C} / 550 \mathrm{MPa} ; \mathbf{c} 980{ }^{\circ} \mathrm{C} /$ $250 \mathrm{MPa} ; \mathbf{d} 1100{ }^{\circ} \mathrm{C} / 140 \mathrm{MPa}$

properties depend on the morphology, size, volume fraction and distribution of the $\gamma^{\prime}$ phase. It has been reported that the $\gamma^{\prime}$ coarsening is responsible for the degradation of the stress rupture properties of single-crystal superalloys after long-term aging [12, 17, 18]. The width of the $\gamma$ matrix channel is enlarged after long-term aging, resulting in the dislocations to easily move in the $\gamma$ matrix. When the $\gamma^{\prime}$ phases are coarsened during thermal exposure, the resistance to the dislocation movement by Orowan's mechanism becomes weak owing to larger width of the $\gamma$ channels [19]. Moreover, the volume fraction of the $\gamma^{\prime}$ phase reduces with increasing aging time, which decreases the precipitation strengthening effect of the aged alloy as well. So the stress rupture life of DD6 alloy after long-term aging at $1100{ }^{\circ} \mathrm{C}$ for $400 \mathrm{~h}$ drops with a large magnitude at different conditions. However, the dislocation shear mechanism is operative at intermediate temperature and high stress. At high temperature and lower stress, deformation is dominated by dislocation bypassing [20]. The difference in deformation mechanism leads to various loss of the stress rupture life of the alloy at different test conditions.

It can be seen from Fig. 3 that the TCP phase precipitates in the alloy after long-term aging for $400 \mathrm{~h}$. This is the second reason for the decrease in the stress rupture life of the aged alloy. The TCP phase is detrimental to stress rupture properties of the alloys [17, 20]. The TCP phase is brittle and destroys the continuity of the microstructure. Moreover, the solid solution strengthening elements in the alloy, such as Re and W, are enriched in the TCP phase, as shown in Fig. 4 and Table 1, which results in poor Re and $\mathrm{W}$ in the matrix surrounding the TCP phase and decreases the solid solution strengthening of the matrix. The TCP phase has complex lattice structures, which lack multiple slip systems. Therefore, they usually provide the source for crack initiation, as shown in Fig. 5c, f, i and 1.

Formation of regular and perfect $\gamma^{\prime}$ rafts has a good effect on the stress rupture life of the single-crystal superalloy [21]. There are a small part of P-type rafts in the stress-ruptured specimens after long-term aging. The existence of P-type rafts destroyed the regular and perfect $\mathrm{N}$-type raft and should be responsible for the degradation of stress rupture properties of the alloy [22].

A rejuvenation heat treatment should regenerate the original microstructure and reverses the deleterious effects of $\gamma^{\prime}$ precipitate coarsening and TCP phases [5]. The equilibrium phases of DD6 alloy were investigated employing the JMatPro software and relevant single-crystal 

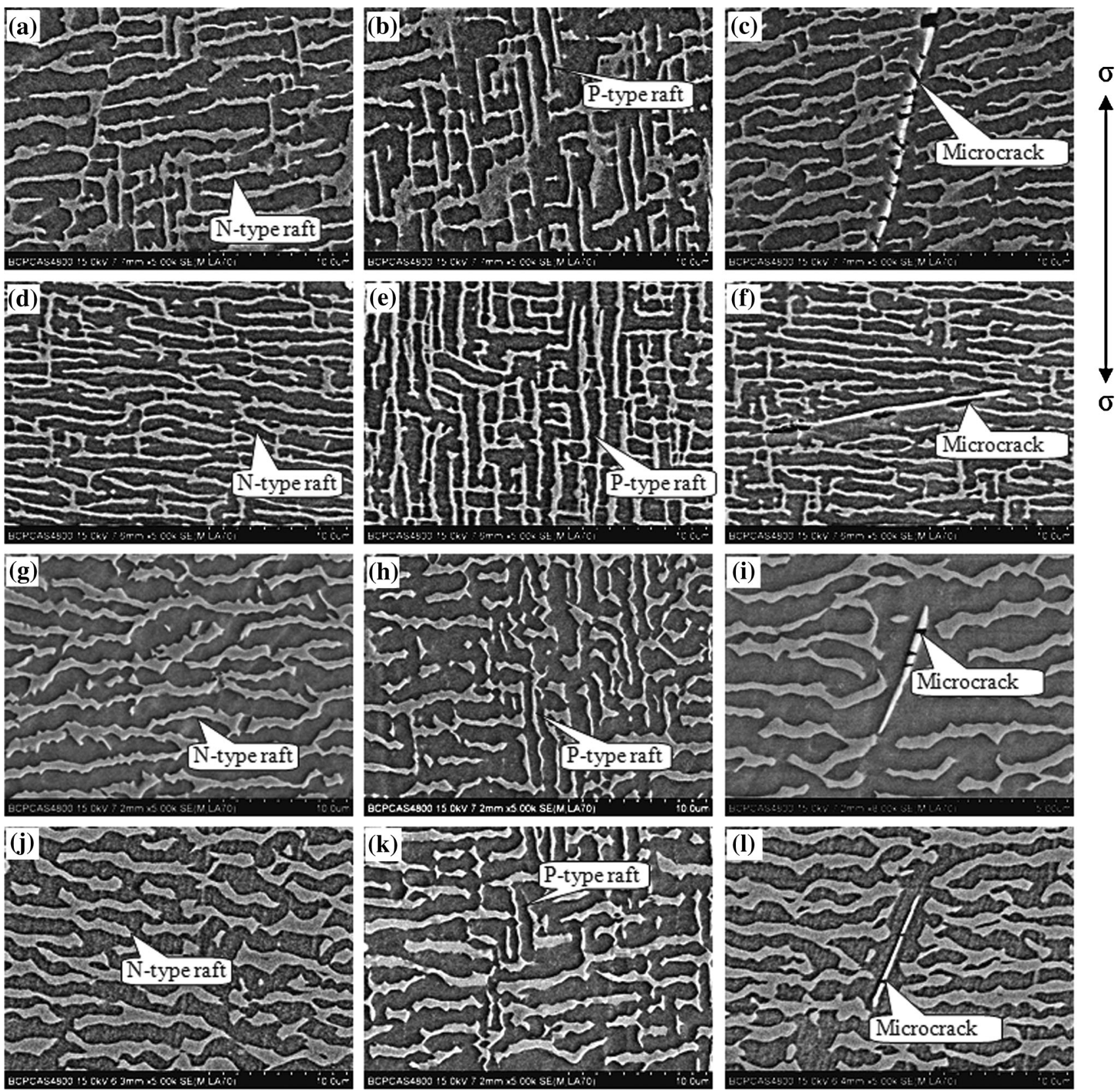

Fig. 5 Microstructures of the stress-ruptured specimens after long-term aging at $1100{ }^{\circ} \mathrm{C}$ for $400 \mathrm{~h}$ : $\mathbf{a}-\mathbf{c} 760{ }^{\circ} \mathrm{C} / 800 \mathrm{MPa} ; \mathbf{d}-\mathbf{f} 850{ }^{\circ} \mathrm{C} / 550 \mathrm{MPa}$; g-i $980{ }^{\circ} \mathrm{C} / 250 \mathrm{MPa} ; \mathbf{j}-\mathbf{l} 1100{ }^{\circ} \mathrm{C} / 140 \mathrm{MPa}$

superalloy database. The calculation results of precipitation phases of the alloy with temperature are shown in Fig. 7. There are $\gamma^{\prime}$ precipitates, $\gamma$ matrix, carbide and TCP, the four phases in the equilibrium phases of the alloy. With increasing temperature, the volume fraction of $\gamma^{\prime}$ and $\operatorname{TCP}(\mu)$ phases decreases and the volume fraction of $\gamma$ matrix increases. The carbide has almost no obviously change because the alloys contain a very little amount of C. The completely dissolved temperatures of the $\operatorname{TCP}(\mu)$ phase and $\gamma^{\prime}$ phase are 1130 and $1295{ }^{\circ} \mathrm{C}$, respectively. So the TCP and $\gamma^{\prime}$ phases can be taken into solution during the rejuvenation heat treatment because the temperature $1300{ }^{\circ} \mathrm{C}$ is high enough. It can be seen from Fig. 3 that the coarsened $\gamma^{\prime}$ phase and TCP phase dissolved entirely after rejuvenation heat treatment. The success of a rejuvenation treatment is typically assessed in terms of stress rupture life recovery [6]. The stress rupture life of the alloy after rejuvenation heat treatment all restores to the original specimen more than $80 \%$ at different conditions. It indicates that the rejuvenation heat treatment of the alloy is successful and the proper mechanical properties can be obtained by it. 

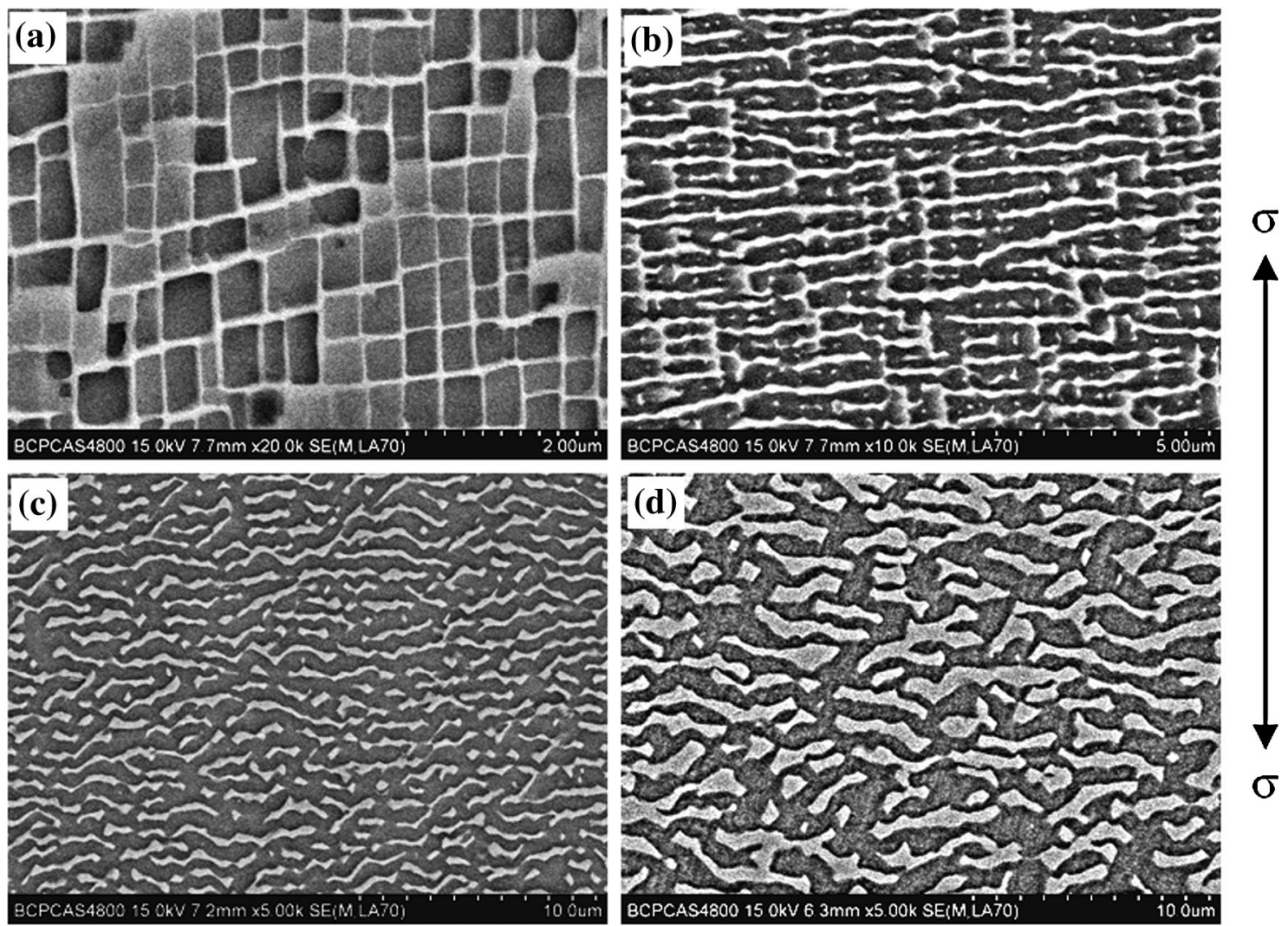

Fig. 6 Microstructures of the stress-ruptured specimens after rejuvenation heat treatment: a $760{ }^{\circ} \mathrm{C} / 800 \mathrm{MPa} ; \mathbf{b} 850{ }^{\circ} \mathrm{C} / 550 \mathrm{MPa} ; \mathbf{c} 980{ }^{\circ} \mathrm{C} /$ $250 \mathrm{MPa} ; \mathbf{d} 1100{ }^{\circ} \mathrm{C} / 140 \mathrm{MPa}$

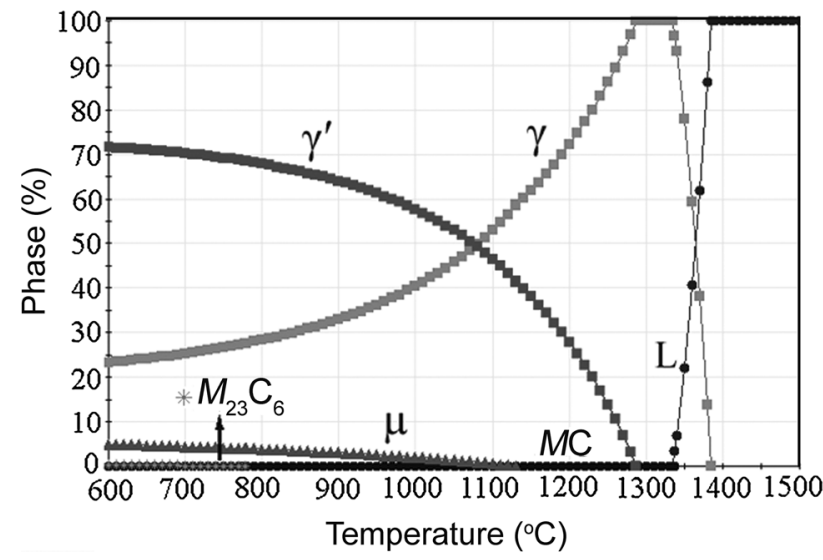

Fig. 7 Calculated dependences of the precipitation phases of DD6 alloy on temperature

\section{Conclusions}

1. The $\gamma^{\prime}$ phase of DD6 alloy became very irregular and larger after long-term aging at $1100{ }^{\circ} \mathrm{C}$ for $400 \mathrm{~h}$. A very small amount of needle-shaped TCP phase precipitated in the dendrite core. The TCP phase with high
Re and $\mathrm{W}$ contents precipitates and grows along a fixed direction.

2. The coarsened $\gamma^{\prime}$ phase and TCP phase dissolved entirely after rejuvenation heat treatment. The microstructure was restored and almost same with the original microstructure. During rejuvenation, the heat treatment can restore the microstructure to its original condition as much as possible.

3. The stress rupture life of the alloy decreased in different degrees at various test conditions after longterm aging. The long-term aging at high temperature has much effect on the stress rupture property of the alloy at intermediate temperature and high stress. The stress rupture life of the alloy after rejuvenation heat treatment all restores to the original specimen more than $80 \%$ at different conditions.

4. The microstructure degradation of the alloy during long-term aging at $1100{ }^{\circ} \mathrm{C}$ includes coarsening of $\gamma^{\prime}$ precipitates, P-type raft and precipitation of TCP phase, which results in the degeneration of stress rupture property. The rejuvenation heat treatment succeeds in restoring the original microstructure and stress rupture properties. 


\section{References}

[1] P. Caron, T. Khan, Aerosp. Sci. Technol. 3, 513 (1999)

[2] D. Rgence, C. Vernault, Y. Desvallees, D. Fournier, in Superalloys 2000, ed. by T.M. Pollock, R.D. Kissinger, R.R. Bowman, K.A. Green, M. Mclean, S. Olson, J.J. Schirra (TMS, Warrendale, 2000), p. 829

[3] S. Walston, A. Cetel, R. Mackay, K. O'hara, D. Duhl, R. Dreshfield, in Superalloys 2004, ed. by K.A. Green, T.M. Pollock, H. Harada, T.W. Howson, R.C. Reed, J.J. Schirra, S. Walston (TMS, Pennsylvania, 2004), p. 15

[4] Q. Feng, J.Y. Tong, Y.R. Zheng, M.L. Wang, W.J. Wei, H.L. Zhao, X.F. Yuan, X.F. Ding, Mater. China 31(12), 21 (2012). (in Chinese)

[5] A. James, Mater. Sci. Technol. 17, 481 (2001)

[6] L.H. Rettberg, M. Tsunekane, T.M. Pollock, in Superalloys 2012, ed. by E.S. Huron, R.C. Reed, M.C. Hardy, M.J. Mills, R.E. Montero, P.D. Portella, J. Telesman (TMS, Pennsylvania, 2012), p. 341

[7] Z. Yao, C.C. Degnan, M.A.E. Jepson, R.C. Thonson, Mater. Sci. Technol. 29, 775 (2013)

[8] S. Zangeneh, H. Farhangi, H.R. Lashgari, J. Alloys Compd. 497, 360 (2010)

[9] H.S. Lee, D.H. Kim, D.S. Kim, K.B. Yoo, J. Alloys Compd. 561, 135 (2013)

[10] J.R. Li, Z.G. Zhong, D.Z. Tang, S.Z. Liu, P. Wei, Z.T. Wu, D. Huang, M. Han, in Superalloys 2000, ed. by R.D. Kissinger,
R.R. Bowman, K.A. Green, M. Mclean, S. Olson, J.J. Schirra (TMS, Warrendale, 2000), p. 777

[11] Z.X. Shi, J.R. Li, S.Z. Liu, Y.S. Luo, J.Q. Zhao, Rare Met. Mater. Eng. 39, 1334 (2010)

[12] J.R. Li, H.P. Jin, S.Z. Liu, Rare Met. Mater. Eng. 36, 1784 (2007)

[13] Z.X. Shi, J.R. Li, S.Z. Liu, M. Han, Trans. Nonferrous Met. Soc. China 21, 998 (2011)

[14] Y.L. Ren, T. Jin, H.R. Guan, Z.Q. Hu, Mater. Mech. Eng. 28(3), 10 (2004). (in Chinese)

[15] L.J. Carroll, Q. Feng, J.F. Mansfield, T.M. Pollock, Mater. Sci. Eng. A 457, 292 (2008)

[16] S.G. Tian, J.H. Zhang, H.H. Zhou, H.C. Yang, Y.B. Xu, Z.Q. Hu, Mater. Sci. Eng. A 262, 271 (1999)

[17] R.A. Hobbs, L. Zhang, C.M.F. Rae, S. Tin, Mater. Sci. Eng. A 489, 65 (2008)

[18] M.V. Acharya, G.E. Fuchs, Mater. Sci. Eng. A 381, 143 (2004)

[19] M. Aghair-simonetti, M. Hajjavady, Mater. Sci. Eng. A 487, 388 (2008)

[20] S.G. Tian, J.H. Zhang, H.H. Zhou, H.C. Yang, Y.B. Xu, Z.Q. Hu, Mater. Sci. Eng. A 279, 160 (2000)

[21] Y.S. Luo, J.R. Li, S.Z. Liu, Mater. Eng. (7), 43 (2006). (in Chinese)

[22] Z.X. Shi, J.R. Li, S.Z. Liu, J. Iron. Steel Res. Int. 19(7), 66 (2012) 